\title{
ChrXq27.3 miRNA cluster functions in cancer development
}

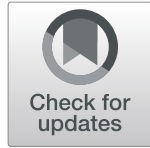

\author{
Kosuke Yoshida ${ }^{1,2,3}$ (D) Akira Yokoi $^{1,2^{*}}$ (D, Yusuke Yamamoto $^{3}$ (D) and Hiroaki Kajiyama ${ }^{1}$ (D)
}

\begin{abstract}
MicroRNAs (miRNAs) regulate the expression of their target genes post-transcriptionally; thus, they are deeply involved in fundamental biological processes. miRNA clusters contain two or more miRNA-encoding genes, and these miRNAs are usually coexpressed due to common expression mechanisms. Therefore, miRNA clusters are effective modulators of biological pathways by the members coordinately regulating their multiple target genes, and an miRNA cluster located on the $X$ chromosome q27.3 region has received much attention in cancer research recently. In this review, we discuss the novel findings of the chrXq27.3 miRNA cluster in various types of cancer. The chrXq27.3 miRNA cluster contains 30 mature miRNAs synthesized from 22 miRNA-encoding genes in an 1.3-Mb region. The expressions of these miRNAs are usually negligible in many normal tissues, with the male reproductive system being an exception. In cancer tissues, each miRNA is dysregulated, compared with in adjacent normal tissues. The miRNA-encoding genes are not uniformly distributed in the region, and they are further divided into two groups (the miR-506-514 and miR-888-892 groups) according to their location on the genome. Most of the miRNAs in the former group are tumor-suppressive miRNAs that are further downregulated in various cancers compared with normal tissues. miR-506-3p in particular is the most well-known miRNA in this cluster, and it has various tumor-suppressive functions associated with the epithelial-mesenchymal transition, proliferation, and drug resistance. Moreover, other miRNAs, such as miR-508-3p and miR-509-3p, have similar tumor-suppressive effects. Hence, the expression of these miRNAs is clinically favorable as prognostic factors in various cancers. However, the functions of the latter group are less understood. In the latter group, miR-888-5p displays oncogenic functions, whereas miR-892b is tumor suppressive. Therefore, the functions of the miR-888-892 group are considered to be cell type- or tissue-specific.

In conclusion, the chrXq27.3 miRNA cluster is a critical regulator of cancer progression, and the miRNAs themselves, their regulatory mechanisms, and their target genes might be promising therapeutic targets.
\end{abstract}

Keywords: miRNA, X chromosome, miRNA cluster, Epithelial-mesenchymal transition, Proliferation, Drug-resistance, miR-506-3p, miR-888-5p

\section{Background}

MicroRNAs (miRNAs), which are small noncoding RNA molecules ( 22 nucleotides in length), regulate gene expression by interacting with the $3^{\prime}$-untranslated regions of genes [1, 2]. Numerous studies have revealed the functions of miRNAs in various cancers [2]. Some

\footnotetext{
* Correspondence: ayokoi@med.nagoya-u.ac.jp

${ }^{1}$ Department of Obstetrics and Gynecology, Nagoya University Graduate School of Medicine, Tsuruma-cho 65, Showa-ku, Nagoya 466-8550, Japan ${ }^{2}$ Institute for Advanced Research, Nagoya University, Nagoya, Japan Full list of author information is available at the end of the article
}

miRNA-encoding genes are located in narrow regions on the genome, which are so-called miRNA clusters; there are 159 miRNA clusters in the human genome [3]. In an miRNA cluster, miRNA-encoding genes can be under the control of a common regulatory unit and are coexpressed [3, 4]. Moreover, members of an miRNA cluster have the same targets or target different genes belonging to specific pathways [3]. One of the most well-known miRNA clusters is the miR-17-92 cluster, which is located on chromosome 13q31.3. This region is 
amplified in lung cancer and B-cell lymphomas, and the expression of the miRNAs derived from the miR-17-92 cluster is substantially increased in these conditions [5, 6]. Functionally, the miR-17-92 cluster is considered an oncogene and acts with $c-m y c$ to promote tumor development [5]. An miRNA cluster located in the chrXq27.3 region (the chrXq27.3 miRNA cluster) has received much attention recently, and the oncogenic or tumorsuppressive functions of this cluster have been elucidated through studies on various cancers.

In this review, we provide an overview of the chrXq27.3 miRNA cluster in cancer progression.

\section{chrXq27.3 miRNA cluster}

The chrXq27.3 miRNA cluster contains 30 mature miRNAs synthesized from 22 miRNA-encoding genes in an $\sim 1.3$ - Mb region (Fig. 1). The miRNA-encoding genes are not uniformly distributed in the region and are separated by a noncoding region of $\sim 1.2-\mathrm{Mb}$. There are 15 miRNA-encoding genes downstream of the noncoding region, and they are named the miR-506-514 group. Similarly, the rest of seven genes are located on the upstream of the noncoding region, and named the miR888-892 groups. Evolutionarily, mammalian species have an miRNA cluster located between the FMR1 and SLITRK2 genes on the $\mathrm{X}$ chromosome, and this miRNA cluster is well conserved among primate species [7-9]. Moreover, mature forms of miRNAs with close loci tend to have similar sequences, and hence, these miRNAs can have common target genes [7, 8].

Many miRNA genes are located inside or close to fragile sites. The chrXq27.3 region is well-known as a key spot for fragile-X syndrome, the most common form of hereditary intellectual disability. This syndrome is responsible for increased CGG repeats in the FMR1 gene [10]. However, it remains unclear whether the chrXq27.3

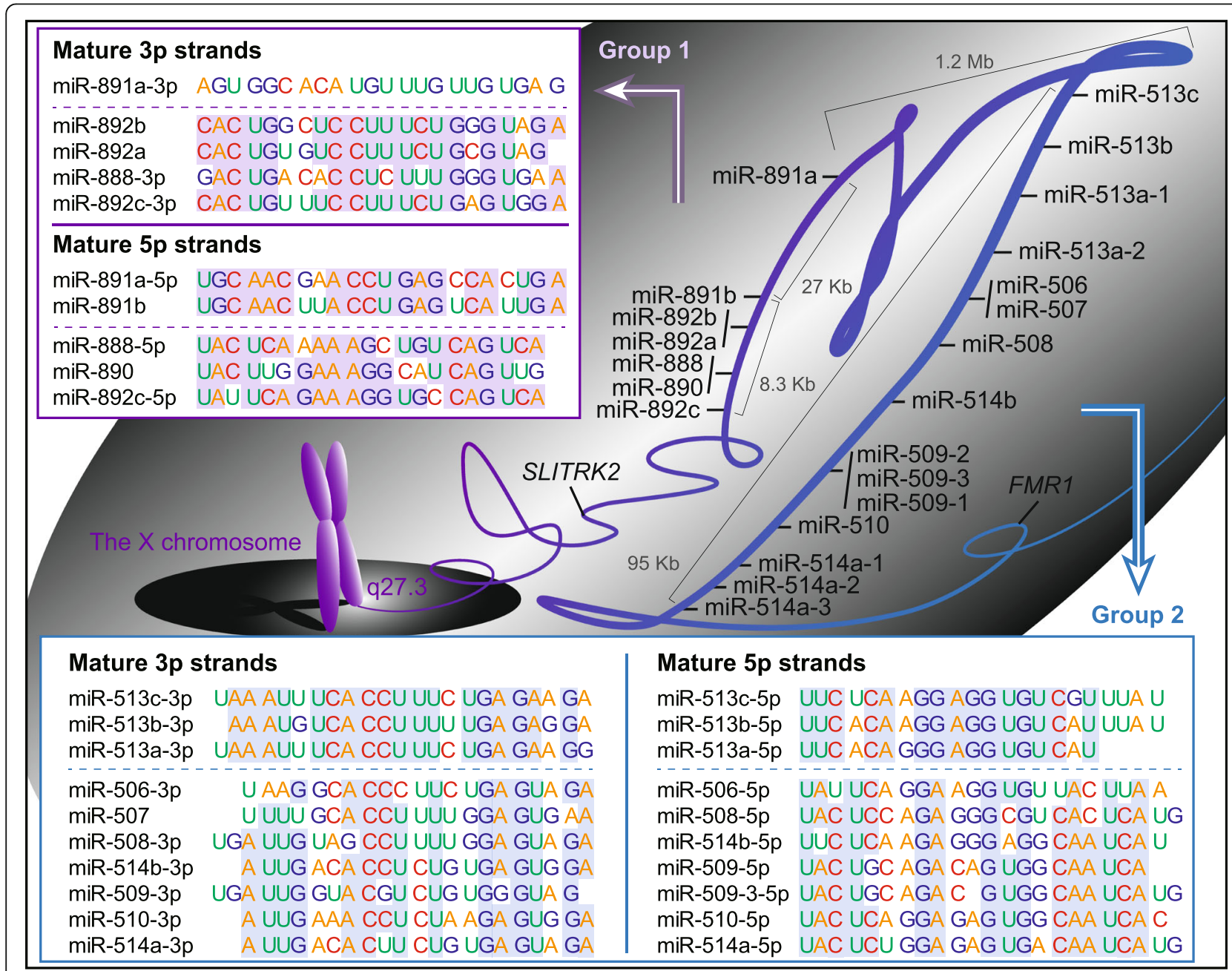

Fig. 1 Schema of the chrXq27.3 miRNA cluster and sequence similarity of the miRNAs in the clusterThere are 22 miRNA-encoding genes in the chrXq27.3 cluster, and they are divided into two groups according to their location. Mature forms of the miRNAs with close loci tend to have similar sequences 
cluster is involved in this syndrome even though some of the miRNAs can target the adjacent gene, FMR1 [9]. Conversely, the expression of these miRNAs is usually negligible in normal tissues except for in the male reproductive system $[8,9,11]$. Thus, this cluster is thought to be involved in testis development and spermatogenesis, and its alteration might be associated with male infertility $[8,9,11,12]$. Additionally, according to Pinheiro's hypothesis, X-linked miRNAs might contribute to the immunological advantage of females as the $\mathrm{X}$ chromosome contains $10 \%$ of all human miRNAs whereas the Y chromosome has no miRNAs, and several X-linked miRNAs have important functions in immunity and cancer [13]. Therefore, the chrXq27.3 miRNA cluster may be important from the aspect of gender differences.

\section{Clinical significance of the chrXq27.3 miRNA cluster in various cancers}

In cancer research, each miRNA is reported to be dysregulated in various cancer tissues compared with in adjacent normal tissues. The most well-known miRNA in the cluster is miR-506-3p, which is commonly downregulated regardless of the type of cancers, including gastric, colorectal, pancreatic, hepatocellular, lung, breast, ovarian, uterine cervical, renal, bladder, nasopharyngeal, and thyroid carcinoma [14-25]. Moreover, as cancer progresses, miR-506-3p expression further decreases, and decreased miR-506-3p expression is associated with poor prognosis in patients with these cancers $[16,18,22$, 26-28] (Table 1). Similarly, the rest of the miR-506-514 group is also tumor-suppressive, and they are frequently downregulated in various cancer tissues compared with normal tissues [29-47]. miR-508-3p and miR-509-3p are further downregulated in cancer cells with treatment resistance; thus, this downregulation is associated with poor survival [48, 49]. Moreover, in breast cancer, low miR-507 and miR-508-3p expression are associated with distant and lymph node metastases, and miR-509-5p and miR-509-3-5p are remarkably decreased in brain metastases compared with primary cancer [31, 50, 51]. Furthermore, several miRNAs in the cluster, including miR-508-3p, miR-509-3p, miR-509-3-5p, and miR-514a-3p, are frequently decreased in advanced and recurrent ovarian carcinoma [52, 53]. Hence, these miRNAs are considered to be coregulated and coexpressed. Other reports have also noted that the expression of these miRNAs is associated with poor prognosis in patients with various cancers [30, 48, 49, 52, 54-56]. However, there are some exceptions. For example, high miR-508-3p expression is associated with shorter disease-free and overall survivals in esophageal squamous cell carcinoma (SCC) [57]. Moreover, high miR-513a-5p expression in breast cancer is a poor prognostic factor [58]. Furthermore, the upregulation of miR-509-5p, miR-510-3p, and miR510-5p has been reported in thyroid and lung cancer, although their prognostic impacts have not been investigated [59-62]. Therefore, the miR-506-514 group, which act as tumor suppressors, is usually downregulated in cancer tissues compared with normal tissues.

Conversely, the miR-888-892 group has both oncogenic and tumor-suppressive functions depending on the miRNAs. miR-888-5p and miR-892a are upregulated in colorectal and hepatocellular carcinoma, and higher miR-888-5p or miR-892a expressions are associated with poor survival (Table 1) [63-66]. However, miR-890 and miR-892b are downregulated in breast cancer, and lower miR-892b expression is associated with a poor prognosis $[67,68]$. Moreover, miR-892b is downregulated in pancreatic and nasopharyngeal cancer tissues, and lower miR891b expression is associated with shorter survival in pancreatic cancer [69-71].

Table 1 Prognostic impact of the chrXq27.3 miRNA cluster

\begin{tabular}{|c|c|c|c|c|c|c|c|c|c|}
\hline & Esophageal & Gastric & Colorectal & Pancreatic & Hepatocellular & Lung & Breast & Ovarian & Renal \\
\hline miR-506-3p & & Favorable & & Favorable & & Favorable & Favorable & Favorable & Favorable \\
\hline miR-507 & & & & & & Favorable & & & \\
\hline miR-508-3p & Poor & & Favorable & & & & & Favorable & \\
\hline miR-508-5p & & Favorable & & & & & & & \\
\hline miR-509-3p & & & & & & & & Favorable & \\
\hline miR-509-5p & & & & Favorable & & & & & \\
\hline miR-513a-5p & & & & & & & Poor & & \\
\hline miR-888-5p & & & Poor & & & & & & \\
\hline miR-891b & & & & Favorable & & & & & \\
\hline miR-892a & & & & & Poor & & & & \\
\hline miR-892b & & & & & & & Favorable & & \\
\hline
\end{tabular}

Favorable, the expression is associated with favorable prognosis; Poor, the expression is associated with poor prognosis 
Therefore, the alteration of the miRNAs in this cluster is frequently observed in various cancers. Moreover, their roles are usually common across cancer types and are considered critical for cancer development.

\section{The functions of the chrXq27.3 miRNA cluster in cancer progression}

The detailed functions of each miRNA in the cluster are described below; however, no reports have yet been published about the following seven miRNAs: miR-513a-3p, miR-513b-3p, miR-513c-3p, miR-888-3p, miR-891a-3p, miR-892c-3p, and miR-892c-5p.

\section{miR-506-3p, miR-506-5p, and miR-507}

One of the most important functions of miR-506-3p is regulation of the epithelial-mesenchymal transition (EMT), which is a critical process to gain migratory and invasive potential in cancer development. Consistent with the clinical tumor-suppressive effect described above, miR-506-3p inhibits EMT by directly targeting key genes of the process; including ZEB2, SNAI2, VIM, and $C D H 2$ (Fig. 2) [14, 20, 27, 28, 72]. Moreover, through regulating other target genes, miR-506-3p induces the downregulation of VIM, SNAIL2, TWIST, and $C D H 2$ and the upregulation of $C D H 1$ [17, 25-27, 7375]. Furthermore, miR-506-3p contributes to maintenance of the tumor microenvironment by decreasing $M M P 9$ expression and inhibiting angiogenesis [26, 76]. Therefore, miR-506-3p is an important regulator of cancer invasion and metastasis.

In addition to inhibiting the EMT, miR-506-3p suppresses proliferation by directly targeting $C D K 4 / 6$. Other target genes such as GLI3, ROCK1, and NR4A1 are also involved in miR-506-3p-induced cell cycle arrest [21, 77-80]. Moreover, miR-506-3p modulates the NF- $\mathrm{kB}$ and Hippo signaling pathways and is associated with tumor suppression [15, 16, 81, 82]. Thus, miR-506-3p can enhance the efficacy of anti-cancer drugs and can sensitize cancer cells to DNA damage by targeting RAD51, GLI3, and SPHK1 (Fig. 3) [16, 21, 83]. Furthermore, many other target genes of miR-506-3p are reported to be associated with cancer progression [19, 2224, 84, 85]. Additionally, MALAT1 and NEAT1, which are long noncoding RNA (lncRNA), can modulate miR506-3p expression [74, 86, 87]. Therefore, miR-506-3p is a common tumor suppressor across various cancers, and miR-506-3p-associated genes can be therapeutic targets.

However, the functions of miR-506-5p remain largely unknown. In hepatocellular carcinoma cells, miR-506-5p suppresses proliferation, migration, and invasion by regulating SPON1 (Fig. 2) [29]. A recent study showed that miR-506-5p also induces the downregulation of $V I M, C D H 2$, and $M M P 9$ and the upregulation of $C D H 1$ in glioma cells [88]. Therefore, miR-506-5p and miR506-3p might coordinately regulate the EMT.

The miR-507 encoding gene is located only $\sim 300 \mathrm{bp}$ downstream of the miR-506 encoding gene, and the mature sequence of miR-507 is similar to that of miR-5063p. Therefore, miR-507 also directly targets ZEB2 and $V E G F R-1$ and contributes to cell migration and invasion (Fig. 2) [30, 50]. Moreover, miR-507 enhances platinum sensitivity via targeting NRF2 and ELK3 (Fig. 3) [89, 90]. Furthermore, miR-507 decreases glucose uptake and lactate production by targeting PDK4; thus, IncRNA LINC00243 promotes proliferation and glycolysis by sponging miR-507 [91]. Overall, these miRNAs function as tumor-suppressive miRNAs in variety of cell types.

\section{miR-508-3p and miR-508-5p}

A network biology analysis revealed that miR-508-3p is strongly associated with mesenchymal properties in ovarian cancer, and it indirectly regulates multiple EMTassociated genes (Fig. 2) [48]. Other reports have highlighted the direct interaction between miR-508-3p and ZEB1 [31, 54]. Moreover, in addition to the EMT, miR-508-3p regulates stemness by targeting $B M I 1$ and SALL4 [54]. Furthermore, NFKB1 is targeted by miR508-3p; thus, miR-508-3p downregulation contributes to canonical NF- $\kappa B$ activation [92]. Therefore, miR-508-3p has similar functions as miR-506-3p and is a strong tumor suppressor. Hence, lncRNAs silence the expression of miR-508-3p and exert their oncogenic functions [32, 54]. However, miR-508-3p may display an opposition function in esophageal SCC. A previous report showed that miR-508-3p sustained PI3K/Akt signaling by targeting the tumor suppressive genes PTEN, INPP5J, and INPP4A, resulting in an increasingly aggressive phenotype of esophageal SCC (Fig. 4) [57].

miR-508-5p targets MAPK1 and suppresses the EMT by modulating MAPK/ERK signaling (Fig. 2) [36]. Moreover, miR-508-5p attenuates proliferation and invasion by targeting FN1 and MESDC1 [35, 37]. In gastric cancer cells, miR-508-5p reverses resistance to doxorubicin, vincristine, 5-fluorouracil, and cisplatin by targeting $A B C B 1$ and ZNRD1 (Fig. 3) [55]. Therefore, except for miR-508-3p in esophageal SCC, these miRNAs act as tumor suppressors.

\section{miR-509-3p, miR-509-5p, and miR-509-3-5p}

In a narrow region of $\sim 2 \mathrm{~Kb}$, there are three precursors of the miR-509 family: miR-509-1, miR-509-2, and miR509-3 (Fig. 1). Although their 3p strands are similar, miR-509-1 and miR-509-2 synthesize miR-509-5p whereas miR-509-3 synthesizes miR-509-3-5p.

Similar to the miRNAs previously described, miR-509$3 p$ is a tumor suppressor and exerts tumor-suppressive effects by targeting several critical regulators, including 
Tumor-suppressive miRNAs and their target genes involving EMT process

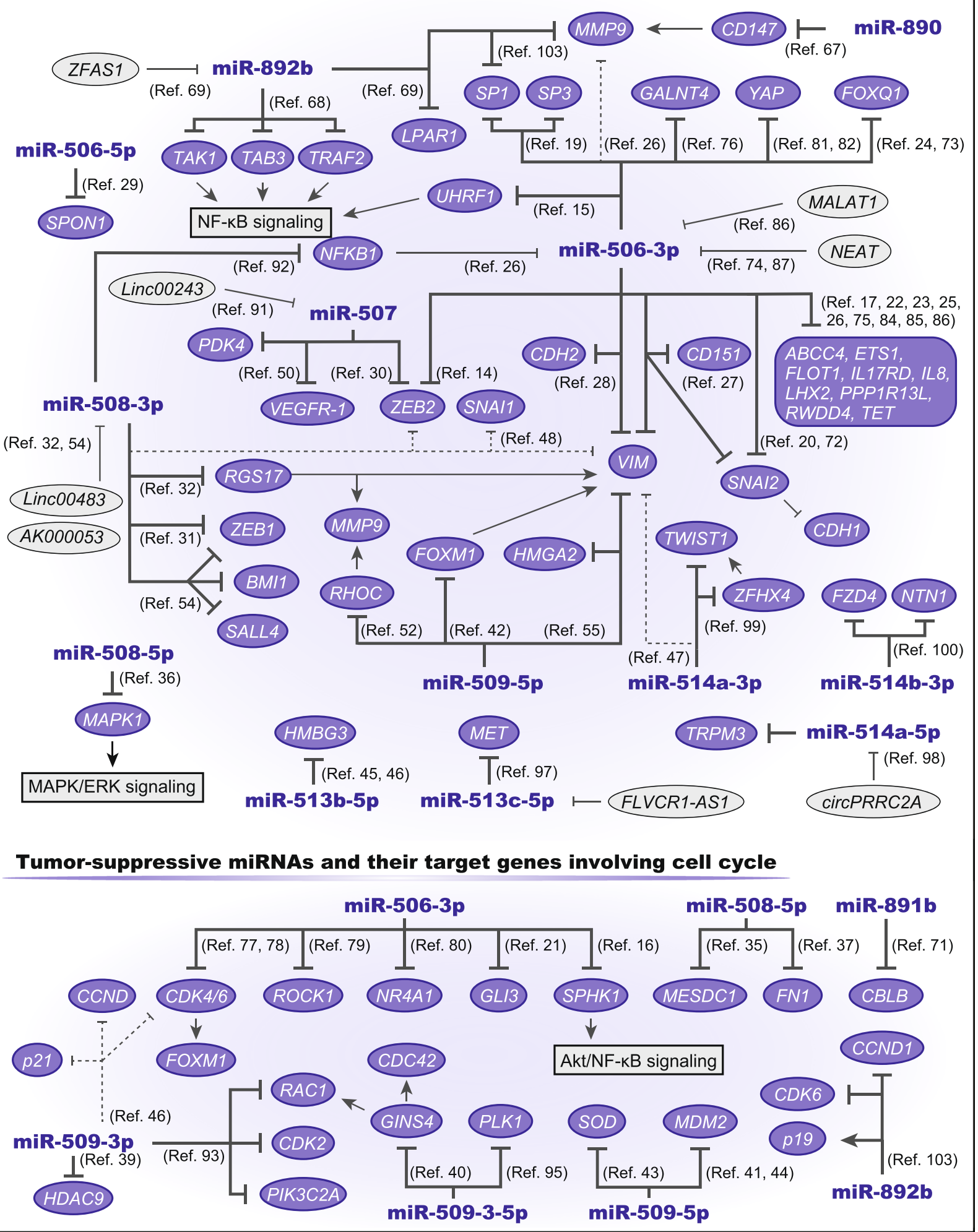

Fig. 2 Tumor-suppressive roles of the chrXq27.3 miRNA clusterMany miRNAs in the cluster act as tumor suppressors by targeting various genes involved in the epithelial-mesenchymal transition and proliferation. Previously validated interactions between the miRNAs and genes or noncording RNAs are described 


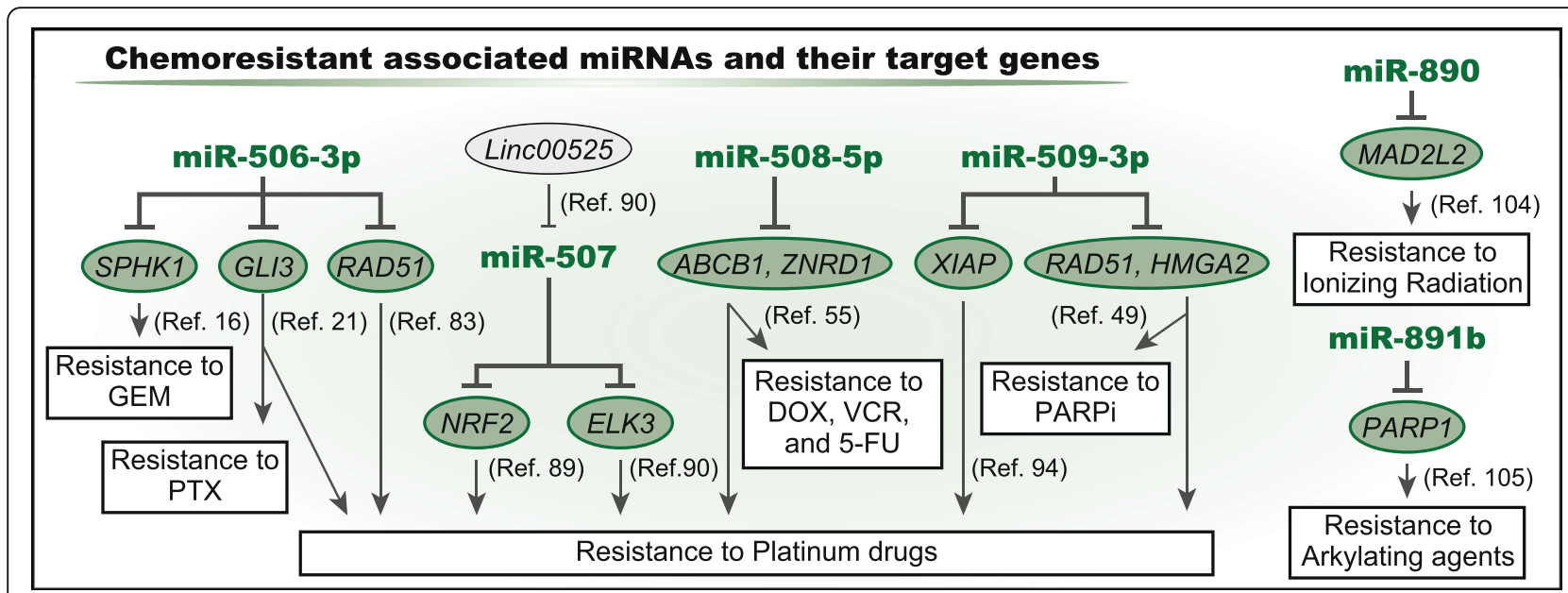

Fig. 3 Treatment resistance and the chrXq27.3 miRNA clusterSeveral miRNAs in the cluster are involved in treatment resistance, and their previously validated functions are described

CDK2, RAC1, and PIK3C2A (Fig. 2) [93]. Moreover, miR-509-3p inhibits proliferation and increases apoptosis by targeting HDAC9 [39]. miR-509-3p also plays a role in treatment resistance by sensitizing ovarian cancer cells to cisplatin and olaparib by targeting XIAP, HMGA2, and RAD51 (Fig. 3) [49, 94].

miR-509-5p has similar target genes, VIM and HMGA2 (Fig. 2) [56]. miR-509-5p inhibits EMT and proliferation by targeting FOXM1, MDM2, and SOD [41-44]. In a mouse model, miR-509-5p was shown to protect brain metastasis by targeting two essential genes, RHOC and TNF [51]. Needless to say, miR-509-3-5p has a very similar sequence to miR-509-5p, and thus they might have common target genes (Fig. 1). miR-509-3-5p suppresses the activation of RAC1 and CDC42 by targeting GINS4 and induces G2/M arrest by targeting PLK1 [40, 95]. Thus, these miRNAs are tumor suppressive. However, in papillary thyroid carcinoma, miR-509-5p displays oncogenic functions and promotes activation of the $\mathrm{Wnt} / \beta$-catenin signaling pathway by targeting SFRP1, resulting increased proliferative and invasive abilities (Fig. 4) [59]. Therefore, the three miRNAs mainly display tumor-suppressive functions.

miR-510-3p and miR-510-5p

As described previously, miR-510-3p and miR-510-5p are upregulated in clinical cancer samples, but their

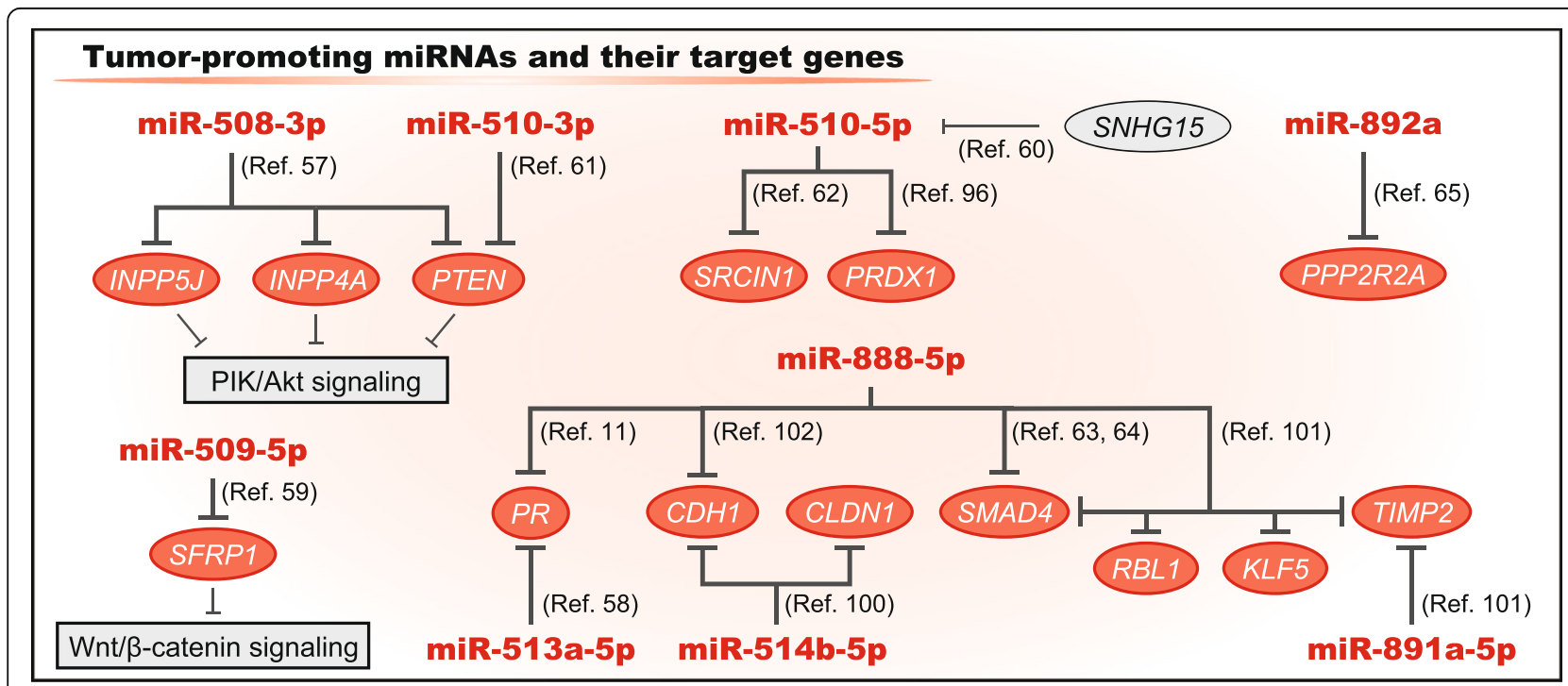

Fig. 4 Tumor-promotive roles of the chrXq27.3 miRNA clusterSome miRNAs in the cluster also act in an oncogenic manner by targeting various genes. Previously validated interactions between the miRNAs and genes or non-cording RNAs are described 
impact on patient prognosis remains uncertain. Functionally, miR-510-3p promotes cancer proliferation and suppresses apoptosis by targeting PTEN in non-small cell lung cancer (Fig. 4) [61]. Moreover, miR-510-5p, which can be regulated by lncRNA SNHG15, promotes proliferation, migration, and invasion via targeting $S R C I$ $N 1$ and PRDX1 in several cancer cells [60, 62, 96]. Therefore, it is interesting that the two miRNAs are oncogenic even though they have similar sequences to other neighboring miRNAs.

\section{miR-513 family}

There are four precursors and six mature forms of the miR-513 family although their functions are largely unknown (Fig. 1). However, no previous reports have described their $3 p$ strands. In breast cancer cells, miR513a-5p decreases the expression of $P R$, and it confers resistance to serum starvation stress (Fig. 4) [58]. Hence, miR-513a-5p may be associated with hormone-mediated carcinogenesis. On the other hand, miR-513b-5p overexpression suppresses tumor progression and promotes apoptosis via targeting $H M B G 3$ (Fig. 2) [45, 46]. Moreover, lncRNA FLVCR1-AS1 promotes cancer progression via sponging miR-513c-5p, which targets $M E T$ [97]. Therefore, miR-513b-5p and miR-513c-5p are tumorsuppressive.

\section{miR-514 family}

Three precursors of miR-514a synthesize the same mature miRNAs (Fig. 1), and similar to other miRNAs in the cluster, the miR-514 family is involved in the EMT process. In renal cell carcinoma, miR-514a-3p and miR514a-5p inhibit EMT by targeting EGFR and TRPM3, respectively (Fig. 2) [47, 98]. Moreover, in lung adenocarcinoma, poor prognostic factors of TWIST1 and ZFHX4 are targeted by miR-514a-3p, and ZFHX4 exerts oncogenic functions by regulating TWIST1 [99].

The roles of miR-514b-3p and miR-514b-5p are unique and opposite. In colorectal cancer, miR-514b-3p inhibits EMT by targeting FZD4 and NTN1, whereas miR-514b-5p promotes the EMT by targeting $C D H 1$ and CLDN1 (Fig. 2\&4) [100]. Therefore, the miR-514 family regulates the EMT process.

\section{miR-888-892 group}

The miR-888-892 group is located $\sim 1.2 \mathrm{Mb}$ upstream of the miR-506-514 group (Fig. 1); thus, these group have different sequences and functions. The members of the miR-888-892 group are upregulated in the metastatic prostate cancer cells PC3-ML compared with PC3$\mathrm{N}$ [101]. Several reports show that miR-888-5p is oncogenic and promotes the EMT in several cell lines by targeting SMAD4, TIMP2, and CDH1 (Fig. 4) [63, 64, 101, 102]. Moreover, RBL1 and KLF5 are other target genes of miR-888-5p that might be involved in this function [101]. In hormone-dependent endometrial cancer, miR888-5p can act as an oncomiR by targeting $P R$ [11] Therefore, miR-888-5p is a key miRNA in the miR-888892 group. Moreover, miR-891a-5p targets TIMP2 and may support the functions of miR-888-5p [101]. Furthermore, miR-892a is also oncogenic and targets $P P P 2 R 2 A$, a regulator of Akt signaling [65].

This group also contains tumor-suppressive miRNAs. Several reports indicate that miR-892b suppresses proliferation, migration, and invasion via targeting multiple genes such as CCND1, CDK6, LPAR1, and multiple mediators of NF-kB signaling (Fig. 2) [68, 69, 103]. Moreover, miR-890 and miR-891b inhibit cancer progression by targeting $C D 147$ and $C B L B$, respectively $[67,71]$. Furthermore, miR-890 and miR-891b were shown to sensitize cancer cells to DNA damage by modulating DNA-repair genes $[104,105]$. Therefore, miR-890, miR891b, and miR-892b are tumor-suppressive.

Based on their genome location, the miR-888-892 group can be coexpressed although each miRNA can act both oncogenic and tumor-suppressive. Therefore, the functions of the miR-888-892 group are more cell typeor tissue-specific than those of the miR-506-514 group.

\section{Future perspectives}

The members of the chrXq27.3 miRNA cluster may coordinately regulate cancer-related pathways. The miRNAs in the miR-506-514 group are particularly strong tumor suppressors, and their downregulation plays important roles in cancer progression. Hence, the regulatory mechanisms of this cluster must be elucidated. According to previous reports, miR-506-3p and miR-507 expressions are reduced due to hypermethylation of their promoter region $[16,50]$. Conversely, p53 contributes to the increased expressions of miR-506-3p and miR-509-5p [44, 106]. Considering the features of miRNA clusters, other miRNAs in this cluster could be regulated by these factors, and the re-activation of tumor-suppressive miRNAs might be a potent therapeutic strategy. Moreover, the location of the cluster makes itself more interesting because the number of $\mathrm{X}$ chromosomes differs between men and women, and it might be responsible for the difference in cancer incidence and immunity between males and females [13].

Additionally, miRNA replacement therapy has been developed, and a phase 1 study about miR-16-based mimic miRNA in malignant pleural mesothelioma was performed [107]. To achieve miRNA replacement therapy in various cancers, a suitable delivery system with a high specificity for targeting cancer cells must be developed. Thus, optimal miRNAs should be selected depending on the cancer types. We believe that the tumorsuppressive miRNAs in this cluster may be suitable 
because their anti-cancer effect is universal regardless of the cancer. However, the rest of the oncogenic miRNAs in the cluster are also attractive therapeutic targets. Inhibiting the miRNAs may potentially have fewer adverse effects because most of the normal tissues show negligible expression of the miRNAs. Therefore, further studies about this cluster are highly anticipated.

\section{Conclusion}

In conclusion, the chrXq27.3 miRNA cluster is a critical regulator of cancer progression in various types of cancer. Among the 30 mature miRNAs in this cluster, miR506-3p is the most well-known tumor suppressor, but there are many miRNAs with unknown functions. Therefore, this cluster is worth evaluating in the future and is a promising therapeutic target.

\section{Abbreviations}

EMT: epithelial-mesenchymal transition; miRNA: microRNA; SCC: squamous cell carcinoma

\section{Acknowledgements}

This study was supported by Practical Research for Innovative Cancer Control, Japan Agency for Medical Research and Development (AMED): Grant Number 20ck0106630h0001, Yokoyama Foundation for Clinical Pharmacology grant number: Grant Number TRY-2014 and Aichi Cancer Research Foundation. Moreover, research reported in this publication was supported by the Program for Promoting the Enhancement of Research Universities as young researcher units for the advancement of new and undeveloped fields at Nagoya University. Furthermore, we would like to thank Enago (https://www.enago.jp/) for the English language review.

\section{Authors' contributions}

Concept and writing of the manuscript: $K Y_{\text {" }}$ critical revision and edition of the paper: AY., YY., and HK. All authors have read and agreed to the published version of the manuscript.

\section{Funding}

Practical Research for Innovative Cancer Control, Japan Agency for Medical Research and Development (AMED): Grant Number 20ck0106630h0001, Yokoyama Foundation for Clinical Pharmacology grant number: Grant Number TRY-2014 and Aichi Cancer Research Foundation.

\section{Availability of data and materials}

Not applicable.

\section{Declarations}

Ethics approval and consent to participate

Not applicable.

\section{Consent for publication}

Not applicable.

\section{Competing interests}

The authors declare no conflict of interest.

\section{Author details}

${ }^{1}$ Department of Obstetrics and Gynecology, Nagoya University Graduate School of Medicine, Tsuruma-cho 65, Showa-ku, Nagoya 466-8550, Japan. ${ }^{2}$ Institute for Advanced Research, Nagoya University, Nagoya, Japan. ${ }^{3}$ Division of Cellular Signaling, National Cancer Center Research Institute, Tokyo, Japan.
Received: 2 February 2021 Accepted: 14 March 2021

Published online: 25 March 2021

\section{References}

1. Bartel DP. MicroRNAs: genomics, biogenesis, mechanism, and function. Cell. 2004;116(2):281-97. https://doi.org/10.1016/S0092-8674(04)00045-5.

2. Esquela-Kerscher A, Slack FJ. Oncomirs - microRNAs with a role in cancer. Nat Rev Cancer. 2006;6(4):259-69. https://doi.org/10.1038/nrc1840.

3. Kabekkodu SP, Shukla V, Varghese VK, Adiga D, Vethil Jishnu P, Chakrabarty $\mathrm{S}$, et al. Cluster miRNAs and cancer: Diagnostic, prognostic and therapeutic opportunities. Wiley Interdiscip Rev RNA. 2020;11(2):e1563. https://doi.org/1 0.1002/wrna.1563.

4. Mendes ND, Freitas AT, Sagot MF. Current tools for the identification of miRNA genes and their targets. Nucleic Acids Res. 2009;37(8):2419-33. https://doi.org/10.1093/nar/gkp145

5. He L, Thomson JM, Hemann MT, Hernando-Monge E, Mu D, Goodson S, Powers S, Cordon-Cardo C, Lowe SW, Hannon GJ, Hammond SM. A microRNA polycistron as a potential human oncogene. Nature. 2005; 435(7043):828-33. https://doi.org/10.1038/nature03552.

6. Hayashita $Y$, Osada H, Tatematsu Y, Yamada H, Yanagisawa K, Tomida S, Yatabe Y, Kawahara K, Sekido Y, Takahashi T. A polycistronic microRNA cluster, miR-17-92, is overexpressed in human lung cancers and enhances cell proliferation. Cancer Res. 2005;65(21):9628-32. https://doi.org/10.1158/ 0008-5472.CAN-05-2352.

7. Zhang R, Peng Y, Wang W, Su B. Rapid evolution of an X-linked microRNA cluster in primates. Genome Res. 2007;17(5):612-7. https://doi.org/10.1101/ gr.6146507

8. Li J, Liu Y, Dong D, Zhang Z. Evolution of an X-linked primate-specific micro RNA cluster. Mol Biol Evol. 2010;27(3):671-83. https://doi.org/10.1093/ molbev/msp284.

9. Ramaiah M, Tan K, Plank TM, Song HW, Dumdie JN, Jones S, et al. A microRNA cluster in the fragile-X region expressed during spermatogenesis targets FMR1. EMBO Rep. 2019;20(2):e46566. https://doi.org/10.15252/embr.2 01846566

10. Razak KA, Dominick KC, Erickson CA. Developmental studies in fragile X syndrome. J Neurodev Disord. 2020;12(1):13. https://doi.org/10.1186/s11689020-09310-9.

11. Hovey AM, Devor EJ, Breheny PJ, Mott SL, Dai D, Thiel KW, Leslie KK. miR888: a novel Cancer-testis antigen that targets the progesterone receptor in endometrial Cancer. Transl Oncol. 2015;8(2):85-96. https://doi.org/10.1016/j. tranon.2015.02.001.

12. Sun J, Niu L, Gao S, Yi X, Chen J. miR-509-5p Downregulation Is Associated With Male Infertility And Acts As A Suppressor In Testicular Germ Cell Tumor Cells Through Targeting MDM2. OncoTargets Ther. 2019;12:1051522

13. Pinheiro I, Dejager L, Libert C. X-chromosome-located microRNAs in immunity: might they explain male/female differences? The $X$ chromosomegenomic context may affect X-located miRNAs and downstream signaling, thereby contributing to the enhanced immune response of females. BioEssays. 2011;33(11):791-802. https://doi.org/10.1002/bies.201100047.

14. Wang GJ, Jiao BP, Liu YJ, Li YR, Deng BB. Reactivation of microRNA-506 inhibits gastric carcinoma cell metastasis through ZEB2. Aging. 2019;11(6): 1821-31. https://doi.org/10.18632/aging.101877.

15. Lin Y, Chen Z, Zheng Y, Liu Y, Gao J, Lin S, Chen S. MiR-506 targets UHRF1 to inhibit colorectal Cancer proliferation and invasion via the KISS1/PI3K/NFkappaB signaling Axis. Front Cell Dev Biol. 2019;7:266. https://doi.org/10.33 89/fcell.2019.00266.

16. Li J, Wu H, Li W, Yin L, Guo S, Xu X, Ouyang Y, Zhao Z, Liu S, Tian Y, Tian Z, Ju J, Ni B, Wang H. Downregulated miR-506 expression facilitates pancreatic cancer progression and chemoresistance via SPHK1/Akt/NF-kappaB signaling. Oncogene. 2016;35(42):5501-14. https://doi.org/10.1038/onc.2016. 90.

17. Wang Z, Si M, Yang N, Zhang H, Fu Y, Yan K, et al. MicroRNA-506 suppresses invasiveness and metastasis of human hepatocellular carcinoma cells by targeting IL8. Am J Cancer Res. 2018;8(8):1586-94.

18. Guo $S$, Yang $P$, Jiang $X$, Li $X$, Wang $Y$, Zhang $X$, Sun B, Zhang $Y$, Jia $Y$. Genetic and epigenetic silencing of mircoRNA-506-3p enhances COTL1 oncogene expression to foster non-small lung cancer progression. Oncotarget. 2017;8(1):644-57. https://doi.org/10.18632/oncotarget.13501.

19. Wang XX, Guo GC, Qian XK, Dou DW, Zhang Z, Xu XD, et al. miR-506 attenuates methylation of IncRNA MEG3 to inhibit migration and invasion 
of breast cancer cell lines via targeting SP1 and SP3. Cancer Cell Int. 2018; 18:171.

20. Yang $D$, Sun Y, Hu L, Zheng H, Ji P, Pecot CV, Zhao Y, Reynolds S, Cheng H, Rupaimoole R, Cogdell D, Nykter M, Broaddus R, Rodriguez-Aguayo C, Lopez-Berestein G, Liu J, Shmulevich I, Sood AK, Chen K, Zhang W. Integrated analyses identify a master microRNA regulatory network for the mesenchymal subtype in serous ovarian cancer. Cancer Cell. 2013;23(2):18699. https://doi.org/10.1016/j.ccr.2012.12.020.

21. Wen SY, Lin Y, Yu YQ, Cao SJ, Zhang R, Yang XM, Li J, Zhang YL, Wang YH, Ma MZ, Sun WW, Lou XL, Wang JH, Teng YC, Zhang ZG. miR-506 acts as a tumor suppressor by directly targeting the hedgehog pathway transcription factor Gli3 in human cervical cancer. Oncogene. 2015;34(6):717-25. https:// doi.org/10.1038/onc.2014.9.

22. Yang FQ, Zhang HM, Chen SJ, Yan Y, Zheng JH. MiR-506 is down-regulated in clear cell renal cell carcinoma and inhibits cell growth and metastasis via targeting FLOT1. PLoS One. 2015;10(3):e0120258. https://doi.org/10.1371/ journal.pone.0120258.

23. Hou Y. MiR-506 inhibits cell proliferation, invasion, migration and epithelialto-mesenchymal transition through targeting RWDD4 in human bladder cancer. Oncol Lett. 2019;17(1):73-8. https://doi.org/10.3892/ol.2018.9594.

24. Zhang Z, Ma J, Luan G, Kang L, Su Y, He Y, Luan F. MiR-506 suppresses tumor proliferation and invasion by targeting FOXQ1 in nasopharyngeal carcinoma. PLoS One. 2015;10(4):e0122851. https://doi.org/10.1371/journal. pone.0122851.

25. Zhu J, Zhang Q, Jin XY, Cai JB, Chen X, Shi WB, Pang WY, Guo GL, Yang $\sqcup$. MiR-506 suppresses papillary thyroid carcinoma cell proliferation and metastasis via targeting IL17RD. Eur Rev Med Pharmacol Sci. 2019;23(7): 2856-62. https://doi.org/10.26355/eurrev_201904_17563.

26. Li Z, Liu Z, Dong S, Zhang J, Tan J, Wang Y, Ge C, Li R, Xue Y, Li M, Wang W, Xiang X, Yang J, Ding H, Geng T, Yao K, Song X. miR-506 inhibits epithelialto-Mesenchymal transition and angiogenesis in gastric Cancer. Am J Pathol. 2015;185(9):2412-20. https://doi.org/10.1016/.j.ajpath.2015.05.017.

27. Arora H, Qureshi R, Park WY. miR-506 regulates epithelial mesenchymal transition in breast cancer cell lines. PloS one. 2013;8(5):e64273.

28. Sun Y, Hu L, Zheng H, Bagnoli M, Guo Y, Rupaimoole R, Rodriguez-Aguayo C, Lopez-Berestein G, Ji P, Chen K, Sood AK, Mezzanzanica D, Liu J, Sun B, Zhang W. MiR-506 inhibits multiple targets in the epithelial-to-mesenchymal transition network and is associated with good prognosis in epithelial ovarian cancer. J Pathol. 2015;235(1):25-36. https://doi.org/10.1002/pa th.4443.

29. Dai W, Huang HL, Hu M, Wang SJ, He HJ, Chen NP, Li MY. microRNA-506 regulates proliferation, migration and invasion in hepatocellular carcinoma by targeting F-spondin 1 (SPON1). Am J Cancer Res. 2015;5(9):2697-707.

30. Lv HL, Li ZL, Song YB. MicroRNA-507 represses the malignant behaviors of non-small cell lung cancer via targeting zinc finger E-box binding homeobox 2. Eur Rev Med Pharmacol Sci. 2019;23(22):9955-64. https://doi. org/10.26355/eurrev_201911_19562.

31. Guo SJ, Zeng HX, Huang P, Wang S, Xie CH, Li SJ. MiR-508-3p inhibits cell invasion and epithelial-mesenchymal transition by targeting ZEB1 in triplenegative breast cancer. Eur Rev Med Pharmacol Sci. 2018;22(19):6379-85. https://doi.org/10.26355/eurrev_201810_16050.

32. Hu P, Zhou G, Zhang X, Song G, Zhan L, Cao Y. Long non-coding RNA Linc00483 accelerated tumorigenesis of cervical cancer by regulating miR508-3p/RGS17 axis. Life Sci. 2019;234:116789. https://doi.org/10.1016/j.lfs.201 9.116789.

33. Zhai Q, Zhou L, Zhao C, Wan J, Yu Z, Guo X, Qin J, Chen J, Lu R. Identification of miR-508-3p and miR-509-3p that are associated with cell invasion and migration and involved in the apoptosis of renal cell carcinoma. Biochem Biophys Res Commun. 2012;419(4):621-6. https://doi. org/10.1016/.jbbrc.2012.02.060.

34. Duan X, Bai J, Wei J, Li Z, Liu X, Xu G. MicroRNA-508-5p suppresses metastasis in human gastric cancer by targeting S-phase kinaseassociated protein 2. Mol Med Rep. 2017;16(2):2163-71. https://doi.org/10.3892/mmr.2017.6793.

35. Wu SG, Huang YJ, Bao B, Wu LM, Dong J, Liu XH, et al. miR-508-5p acts as an anti-oncogene by targeting MESDC1 in hepatocellular carcinoma. Neoplasma. 2017;64(1):40-7. https://doi.org/10.4149/neo_2017_105.

36. Hong L, Wang Y, Chen W, Yang S. MicroRNA-508 suppresses epithelialmesenchymal transition, migration, and invasion of ovarian cancer cells through the MAPK1/ERK signaling pathway. J Cell Biochem. 2018;119(9): 7431-40. https://doi.org/10.1002/jcb.27052.
37. Li S, Wang Q. Hsa_circ_0081534 increases the proliferation and invasion of nasopharyngeal carcinoma cells through regulating the miR-508-5p/FN1 axis. Aging. 2020;12(20):20645-57. https://doi.org/10.18632/aging.103963.

38. Sun J, Li J, Zhang W, Zhang J, Sun S, Li G, Song H, Wan D. MicroRNA-509-3p inhibits Cancer cell proliferation and migration via Upregulation of XIAP in gastric Cancer cells. Oncol Res. 2017;25(3):455-61. https://doi.org/10.3727/ 096504016 X14747283032017.

39. Guan Y, Yang J, Liu X, Chu L. Long noncoding RNA CBR3 antisense RNA 1 promotes the aggressive phenotypes of non-small-cell lung cancer by sponging microRNA-509-3p and competitively upregulating HDAC9 expression. Oncol Rep. 2020;44(4):1403-14. https://doi.org/10.3892/or.2020. 7719.

40. Zhu Z, Yu Z, Rong Z, Luo Z, Zhang J, Qiu Z, Huang C. The novel GINS4 axis promotes gastric cancer growth and progression by activating Rac1 and CDC42. Theranostics. 2019;9(26):8294-311. https://doi.org/10.7150/thno.362 56.

41. Li X, Li Y, Wan L, Chen R, Chen F. miR-509-5p inhibits cellular proliferation and migration via targeting MDM2 in pancreatic cancer cells. OncoTargets Ther. 2017;10:4455-64. https://doi.org/10.2147/OTT.S130378.

42. Ma N, Zhang W, Qiao C, Luo H, Zhang X, Liu D, Zang S, Zhang L, Bai J. The tumor suppressive role of MiRNA-509-5p by targeting FOXM1 in non-small cell lung Cancer. Cell Physiol Biochem. 2016;38(4):1435-46. https://doi.org/1 $0.1159 / 000443086$.

43. Song YH, Wang J, Nie G, Chen YJ, Li X, Jiang X, Cao WH. MicroRNA-509-5p functions as an anti-oncogene in breast cancer via targeting SOD2. Eur Rev Med Pharmacol Sci. 2017;21(16):3617-25.

44. Ren ZJ, Nong XY, Lv YR, Sun HH, An PP, Wang F, et al. Mir-509-5p joins the $\mathrm{Mdm} 2 / \mathrm{p} 53$ feedback loop and regulates cancer cell growth. Cell Death Dis. 2014;5(8):e1387. https://doi.org/10.1038/cddis.2014.327.

45. Chen X, Zhao G, Wang F, Gao F, Luo H, Wang Y, du Y, Chen X, Xue C, Dong Z, Song G. Upregulation of miR-513b inhibits cell proliferation, migration, and promotes apoptosis by targeting high mobility group-box 3 protein in gastric cancer. Tumour Biol. 2014;35(11):11081-9. https://doi.org/10.1007/ s13277-014-2405-Z.

46. Wang J, Sheng Z, Cai Y. Effects of microRNA-513b on cell proliferation, apoptosis, invasion, and migration by targeting HMGB3 through regulation of mTOR signaling pathway in non-small-cell lung cancer. J Cell Physiol. 2019;234(7):10934-41. https://doi.org/10.1002/jcp.27921.

47. Ke X, Zeng X, Wei X, Shen Y, Gan J, Tang H, Hu Z. MiR-514a-3p inhibits cell proliferation and epithelial-mesenchymal transition by targeting EGFR in clear cell renal cell carcinoma. Am J Transl Res. 2017;9(12):5332-46.

48. Zhao L, Wang W, Xu L, Yi T, Zhao X, Wei Y, et al. Integrative network biology analysis identifies miR-508-3p as the determinant for the mesenchymal identity and a strong prognostic biomarker of ovarian cancer. Oncogene. 2018;38:2305-19.

49. Sun C, Cao W, Qiu C, Li C, Dongol S, Zhang Z, Dong R, Song K, Yang X, Zhang Q, Kong B. MiR-509-3 augments the synthetic lethality of PARPi by regulating HR repair in PDX model of HGSOC. J Hematol Oncol. 2020;13(1): 9. https://doi.org/10.1186/s13045-020-0844-0.

50. Jia L, Liu W, Cao B, Li H, Yin C. MiR-507 inhibits the migration and invasion of human breastcancer cells through Flt-1 suppression. Oncotarget. 2016; 7(24):36743-54. https://doi.org/10.18632/oncotarget.9163.

51. Xing F, Sharma S, Liu Y, Mo YY, Wu K, Zhang YY, Pochampally R, Martinez LA, Lo HW, Watabe K. miR-509 suppresses brain metastasis of breast cancer cells by modulating RhoC and TNF-alpha. Oncogene. 2015;34(37):4890-900. https://doi.org/10.1038/onc.2014.412.

52. Bagnoli M, De Cecco L, Granata A, Nicoletti R, Marchesi E, Alberti P, et al. Identification of a chrXq27.3 microRNA cluster associated with early relapse in advanced stage ovarian cancer patients. Oncotarget. 2011;2(12):1265-78. https://doi.org/10.18632/oncotarget.401.

53. Yoshida K, Yokoi A, Sugiyama M, Oda S, Kitami K, Tamauchi S, et al. Expression of the chrXq27.3 miRNA cluster in recurrent ovarian clear cell carcinoma and its impact on cisplatin resistance. Oncogene. 2021;40(7): 1255-68. https://doi.org/10.1038/s41388-020-01595-3.

54. Yan TT, Ren LL, Shen CQ, Wang ZH, Yu YN, Liang Q, Tang JY, Chen YX, Sun DF, Zgodzinski W, Majewski M, Radwan P, Kryczek I, Zhong M, Chen J, Liu Q, Zou W, Chen HY, Hong J, Fang JY. miR-508 defines the stem-like/ Mesenchymal subtype in colorectal Cancer. Cancer Res. 2018;78(7):1751-65. https://doi.org/10.1158/0008-5472.CAN-17-2101.

55. Shang Y, Zhang Z, Liu Z, Feng B, Ren G, Li K, Zhou L, Sun Y, Li M, Zhou J, An Y, Wu K, Nie Y, Fan D. miR-508-5p regulates multidrug resistance of 
gastric cancer by targeting ABCB1 and ZNRD1. Oncogene. 2014;33(25): 3267-76. https://doi.org/10.1038/onc.2013.297.

56. Hiramoto H, Muramatsu T, Ichikawa D, Tanimoto K, Yasukawa S, Otsuji E, et al. miR-509-5p and miR-1243 increase the sensitivity to gemcitabine by inhibiting epithelial-mesenchymal transition in pancreatic cancer. Sci Reports. 2017;7(1):4002

57. Lin C, Liu A, Zhu J, Zhang X, Wu G, Ren P, et al. miR-508 sustains phosphoinositide signalling and promotes aggressive phenotype of oesophageal squamous cell carcinoma. Nature Commun. 2014;5:4620.

58. Muti P, Donzelli S, Sacconi A, Hossain A, Ganci F, Frixa T, Sieri S, Krogh V, Berrino F, Biagioni F, Strano S, Beyene J, Yarden Y, Blandino G. MiRNA-513a$5 p$ inhibits progesterone receptor expression and constitutes a risk factor for breast cancer: the hOrmone and diet in the ETiology of breast cancer prospective study. Carcinogenesis. 2018;39(2):98-108. https://doi.org/10.1 093/carcin/bgx126.

59. Yang C, Wang Y, Yang W, Gao Y, Zhao B, Yang X. MiR-509-5p improves the proliferative and invasive abilities of papillary thyroid carcinoma cells by inhibiting SFRP1. Arch Med Sci. 2019;15(4):968-78. https://doi.org/10.5114/a oms.2019.85904

60. Liu Y, Li J, Li M, Li F, Shao Y, Wu L. microRNA-510-5p promotes thyroid cancer cell proliferation, migration, and invasion through suppressing SNHG15. J Cell Biochem. 2019. https://doi.org/10.1002/jcb.28454.

61. Yu W, Li D, Ding X, Sun Y, Liu Y, Cong J, Yang J, Sun J, Ning X, Wang H, Xu T. LINC00702 suppresses proliferation and invasion in non-small cell lung cancer through regulating miR-510/PTEN axis. Aging. 2019;11(5):1471-85. https://doi.org/10.18632/aging.101846.

62. Wu W, He L, Huang Y, Hou L, Zhang W, Zhang L, Wu C. MicroRNA-510 plays oncogenic roles in non-small cell lung Cancer by directly targeting SRC kinase signaling inhibitor 1. Oncol Res. 2019;27(8):879-87. https://doi.org/1 0.3727/096504018X15451308507747.

63. Gao SJ, Chen L, Lu W, Zhang L, Wang L, Zhu HH. miR-888 functions as an oncogene and predicts poor prognosis in colorectal cancer. Oncol Lett. 2018;15(6):9101-9. https://doi.org/10.3892/ol.2018.8461.

64. Li YB, Sun FN, Ma XY, Qu H, Yu Y. MiR-888 promotes cell migration and invasion of hepatocellular carcinoma by targeting SMAD4. Eur Rev Med Pharmacol Sci. 2019;23(5):2020-7.

65. Liang WL, Cao J, Xu B, Yang P, Shen F, Sun Z, et al. miR-892a regulated PPP2R2A expression and promoted cell proliferation of human colorectal cancer cells. Biomed Pharmacother. 2015;72:119-24.

66. Jia B, Tan L, Jin Z, Jiao Y, Fu Y, Liu Y. MiR-892a promotes hepatocellular carcinoma cells proliferation and invasion through targeting CD226. J Cell Biochem. 2017;118(6):1489-96. https://doi.org/10.1002/jcb.25808.

67. Wang C, Xu C, Niu R, Hu G, Gu Z, Zhuang Z. MiR-890 inhibits proliferation and invasion and induces apoptosis in triple-negative breast cancer cells by targeting CD147. BMC Cancer. 2019;19(1):577. https://doi.org/10.1186/s12885-019-5796-9.

68. Jiang L, Yu L, Zhang X, Lei F, Wang L, Liu X, Wu S, Zhu J, Wu G, Cao L, Liu A, Song L, Li J. miR-892b silencing activates NF-kappaB and promotes aggressiveness in breast Cancer. Cancer Res. 2016;76(5):1101-11. https://doi. org/10.1158/0008-5472.CAN-15-1770.

69. Peng J, Liu F, Zheng H, Wu Q, Liu S. Long noncoding RNA ZFAS1 promotes tumorigenesis and metastasis in nasopharyngeal carcinoma by sponging miR-892b to up-regulate LPAR1 expression. J Cell Mol Med. 2020;24(2): 1437-50. https://doi.org/10.1111/jcmm.14823.

70. Hao L, Rong W, Bai L, Cui H, Zhang S, Li Y, Chen D, Meng X. Upregulated circular RNA circ_0007534 indicates an unfavorable prognosis in pancreatic ductal adenocarcinoma and regulates cell proliferation, apoptosis, and invasion by sponging miR-625 and miR-892b. J Cell Biochem. 2019;120(3): 3780-9. https://doi.org/10.1002/jcb.27658.

71. Dong Q, Li C, Che X, Qu J, Fan Y, Li X, Li Y, Wang Q, Liu Y, Yang X, Qu X. MicroRNA-891b is an independent prognostic factor of pancreatic cancer by targeting Cbl-b to suppress the growth of pancreatic cancer cells. Oncotarget. 2016;7(50):82338-53. https://doi.org/10.18632/oncotarget.11001.

72. Ma HB, Yao YN, Yu JJ, Chen XX, Li HF. Extensive profiling of circular RNAs and the potential regulatory role of circRNA-000284 in cell proliferation and invasion of cervical cancer via sponging miR-506. Am J Transl Res. 2018; 10(2):592-604

73. Zhang M, Xu Q, Yan S, Li Z, Yan W, Jia X. Suppression of forkhead box Q1 by microRNA-506 represses the proliferation and epithelial-mesenchymal transition of cervical cancer cells. Oncol Rep. 2016;35(5):3106-14. https://doi. org/10.3892/or.2016.4651.
74. Yong W, Yu D, Jun Z, Yachen D, Weiwei W, Midie X, Xingzhu J, Xiaohua W. Long noncoding RNA NEAT1, regulated by LIN28B, promotes cell proliferation and migration through sponging miR-506 in high-grade serous ovarian cancer. Cell Death Dis. 2018;9(9):861. https://doi.org/10.1038/s41419018-0908-z.

75. Liang TS, Zheng YJ, Wang J, Zhao JY, Yang DK, Liu ZS. MicroRNA-506 inhibits tumor growth and metastasis in nasopharyngeal carcinoma through the inactivation of the Wnt/beta-catenin signaling pathway by down-regulating LHX2. J Exp Clin Cancer Res. 2019;38(1):97. https://doi. org/10.1186/s13046-019-1023-4.

76. Hu CY, You P, Zhang J, Zhang H, Jiang N. MiR-506-3p acts as a novel tumor suppressor in prostate cancer through targeting GALNT4. Eur Rev Med Pharmacol Sci. 2019;23(12):5133-8. https://doi.org/10.26355/eurrev_201 906_18177.

77. Hossian A, Sajib MS, Tullar PE, Mikelis CM, Mattheolabakis G. Multipronged activity of combinatorial miR-143 and miR-506 inhibits lung Cancer cell cycle progression and angiogenesis in vitro. Sci Rep. 2018;8(1):10495. https://doi.org/10.1038/s41598-018-28872-2.

78. Liu G, Sun Y, Ji P, Li X, Cogdell D, Yang D, Parker Kerrigan BC, Shmulevich I, Chen K, Sood AK, Xue F, Zhang W. MiR-506 suppresses proliferation and induces senescence by directly targeting the CDK4/6-FOXM1 axis in ovarian cancer. J Pathol. 2014;233(3):308-18. https://doi.org/10.1002/path.4348.

79. Deng Q, Xie L, Li H. MiR-506 suppresses cell proliferation and tumor growth by targeting rho-associated protein kinase 1 in hepatocellular carcinoma. Biochem Biophys Res Commun. 2015;467(4):921-7. https://doi.org/10.1016/j. bbrc.2015.10.043.

80. Huang M, Xie X, Song X, Gu S, Chang X, Su T, Liang B, Huang D. MiR-506 suppresses colorectal Cancer development by inhibiting orphan nuclear receptor NR4A1 expression. J Cancer. 2019;10(15):3560-70. https://doi.org/1 $0.7150 / j c a .28272$.

81. Wang L, Zhang Z, Yu X, Huang X, Liu Z, Chai Y, Yang L, Wang Q, Li M, Zhao J, Hou J, Li F. Unbalanced YAP-SOX9 circuit drives stemness and malignant progression in esophageal squamous cell carcinoma. Oncogene. 2019; 38(12):2042-55. https://doi.org/10.1038/s41388-018-0476-9.

82. Gao C, Hu S. miR-506 is a YAP1-dependent tumor suppressor in laryngeal squamous cell carcinoma. Cancer Biol Ther. 2019;20(6):826-36. https://doi. org/10.1080/15384047.2018.1564569.

83. Liu G, Yang D, Rupaimoole R, Pecot CV, Sun Y, Mangala LS, et al. Augmentation of response to chemotherapy by microRNA-506 through regulation of RAD51 in serous ovarian cancers. J Natl Cancer Institute. 2015; 107(7):djv108. https://doi.org/10.1093/jnci/djv108.

84. Wu M, Zhang Y, Tang A, Tian L. miR-506 inhibits cell proliferation and invasion by targeting TET family in colorectal cancer. Iran J Basic Med Sci. 2016;19(3):316-22.

85. Gong M, Chen C, Zhao H, Sun M, Song M. miR-506 suppresses cervical cancer cell proliferation both in vitro and in vivo. Neoplasma. 2018;65(3): 331-8. https://doi.org/10.4149/neo_2018_170112N25.

86. Lei R, Xue M, Zhang L, Lin Z. Long noncoding RNA MALAT1-regulated microRNA 506 modulates ovarian cancer growth by targeting iASPP. OncoTargets Therapy. 2017;10:35-46. https://doi.org/10.2147/OTT.S112686.

87. Huang B, Liu C, Wu Q, Zhang J, Min Q, Sheng T, Wang X, Zou Y. Long noncoding RNA NEAT1 facilitates pancreatic cancer progression through negative modulation of miR-506-3p. Biochem Biophys Res Commun. 2017; 482(4):828-34. https://doi.org/10.1016/j.bbrc.2016.11.120.

88. Zhao J, Zeng XB, Zhang HY, Xiang JW, Liu YS. Long non-coding RNA FOXD2-AS1 promotes cell proliferation, metastasis and EMT in glioma by sponging miR-506-5p. Open Med. 2020;15(1):921-31.

89. Yamamoto S, Inoue J, Kawano T, Kozaki K, Omura K, Inazawa J. The impact of miRNA-based molecular diagnostics and treatment of NRF2-stabilized tumors. Mol Cancer Res. 2014;12(1):58-68. https://doi.org/10.1158/15417786.MCR-13-0246-T.

90. Wang S, Li J, Yang X. Long non-coding RNA LINC00525 promotes the Stemness and Chemoresistance of colorectal Cancer by targeting miR-507/ ELK3 Axis. Int J Stem Cells. 2019;12(2):347-59. https://doi.org/10.15283/ijsc1 9041.

91. Feng X, Yang S. Long non-coding RNA LINC00243 promotes proliferation and glycolysis in non-small cell lung cancer cells by positively regulating PDK4 through sponging miR-507. Mol Cell Biochem. 2020;463(1-2):127-36. https://doi.org/10.1007/s11010-019-03635-3. 
92. Huang T, Kang W, Zhang B, Wu F, Dong Y, Tong JH, et al. miR-508-3p concordantly silences NFKB1 and RELA to inactivate canonical NF-kappaB signaling in gastric carcinogenesis. Molecular Cancer. 2016;15:9.

93. Yoon S, Han E, Choi YC, Kee H, Jeong Y, Yoon J, Baek K. Inhibition of cell proliferation and migration by miR-509-3p that targets CDK2, Rac1, and PIK3C2A. Molecules Cells. 2014;37(4):314-21. https://doi.org/10.14348/ molcells.2014.2360

94. Chen W, Zeng W, Li X, Xiong W, Zhang M, Huang Y, Zhou L, Jiang S. MicroRNA-509-3p increases the sensitivity of epithelial ovarian cancer cells to cisplatin-induced apoptosis. Pharmacogenomics. 2016;17(3):187-97. https://doi.org/10.2217/pgs.15.166.

95. Wang XH, Lu Y, Liang JJ, Cao JX, Jin YQ, An GS, Ni JH, Jia HT, Li SY. MiR-5093-5p causes aberrant mitosis and anti-proliferative effect by suppression of PLK1 in human lung cancer A549 cells. Biochem Biophys Res Commun. 2016:478(2):676-82. https://doi.org/10.1016/j.bbrc.2016.08.006.

96. Guo QJ, Mills JN, Bandurraga SG, Nogueira LM, Mason NJ, Camp ER, Larue AC, Turner DP, Findlay VJ. MicroRNA-510 promotes cell and tumor growth by targeting peroxiredoxin1 in breast cancer. Breast Cancer Res. 2013;15(4): R70. https://doi.org/10.1186/bcr3464.

97. Zhang K, Zhao Z, Yu J, Chen W, Xu Q, Chen L. LncRNA FLVCR1-AS1 acts AS miR-513c sponge to modulate cancer cell proliferation, migration, and invasion in hepatocellular carcinoma. J Cell Biochem. 2018;119(7):6045-56. https://doi.org/10.1002/jcb.26802.

98. Li W, Yang FQ, Sun CM, Huang JH, Zhang HM, Li X, Wang GC, Zhang N, Che JP, Zhang WT, Yan Y, Yao XD, Peng B, Zheng JH, Liu M. circPRRC2A promotes angiogenesis and metastasis through epithelial-mesenchymal transition and upregulates TRPM3 in renal cell carcinoma. Theranostics. 2020;10(10):4395-409. https://doi.org/10.7150/thno.43239.

99. Xia W, Mao Q, Chen B, Wang L, Ma W, Liang Y, Zhang T, Dong G, Xu L, Jiang F. The TWIST1-centered competing endogenous RNA network promotes proliferation, invasion, and migration of lung adenocarcinoma. Oncogenesis. 2019;8(11):62. https://doi.org/10.1038/s41389-019-0167-6.

100. Ren LL, Yan TT, Shen CQ, Tang JY, Kong X, Wang YC, Chen J, Liu Q, He J, Zhong M, Chen HY, Hong J, Fang JY. The distinct role of strand-specific miR-514b-3p and miR-514b-5p in colorectal cancer metastasis. Cell Death Dis. 2018;9(6):687. https://doi.org/10.1038/s41419-018-0732-5.

101. Hasegawa T, Glavich GJ, Pahuski M, Short A, Semmes OJ, Yang L, Galkin V, Drake R, Esquela-Kerscher A. Characterization and evidence of the miR-888 cluster as a novel Cancer network in prostate. Mol Cancer Res. 2018;16(4): 669-81. https://doi.org/10.1158/1541-7786.MCR-17-0321.

102. Huang S, Cai M, Zheng Y, Zhou L, Wang Q, Chen L. miR-888 in MCF-7 side population sphere cells directly targets E-cadherin. J Genet Genomics. 2014; 41(1):35-42. https://doi.org/10.1016/j.jgg.2013.12.002.

103. Shin SS, Park SS, Hwang B, Moon B, Kim WT, Kim WJ, Moon SK. MicroRNA892b influences proliferation, migration and invasion of bladder cancer cells by mediating the p19ARF/cyclin D1/CDK6 and Sp-1/MMP-9 pathways. Oncol Rep. 2016;36(4):2313-20. https://doi.org/10.3892/or.2016.5052.

104. Hatano K, Kumar B, Zhang Y, Coulter JB, Hedayati M, Mears B, Ni X, Kudrolli TA, Chowdhury WH, Rodriguez R, DeWeese TL, Lupold SE. A functional screen identifies miRNAs that inhibit DNA repair and sensitize prostate cancer cells to ionizing radiation. Nucleic Acids Res. 2015;43(8):4075-86. https://doi.org/10.1093/nar/gkv273.

105. Xu S, Zhao C, Jia Z, Wang X, Han Y, Yang Z. Down-regulation of PARP1 by miR-891b sensitizes human breast cancer cells to alkylating chemotherapeutic drugs. Arch Gynecol Obstet. 2017;296(3):543-9. https:// doi.org/10.1007/s00404-017-4444-3.

106. Yin M, Ren X, Zhang X, Luo Y, Wang G, Huang K, Feng S, Bao X, Huang K, He $X$, Liang $P$, Wang $Z$, Tang $H$, He J, Zhang B. Selective killing of lung cancer cells by miRNA-506 molecule through inhibiting NF-KB p65 to evoke reactive oxygen species generation and p53 activation. Oncogene. 2015; 34(6):691-703. https://doi.org/10.1038/onc.2013.597.

107. van Zandwijk N, Pavlakis N, Kao SC, Linton A, Boyer MJ, Clarke S, Huynh Y, Chrzanowska A, Fulham MJ, Bailey DL, Cooper WA, Kritharides L, Ridley L, Pattison ST, MacDiarmid J, Brahmbhatt H, Reid G. Safety and activity of microRNA-loaded minicells in patients with recurrent malignant pleural mesothelioma: a first-in-man, phase 1, open-label, dose-escalation study. Lancet Oncol. 2017;18(10):1386-96. https://doi.org/10.1016/S1470-2045(17)3 0621-6

\section{Publisher's Note}

Springer Nature remains neutral with regard to jurisdictional claims in published maps and institutional affiliations.
Ready to submit your research? Choose BMC and benefit from:

- fast, convenient online submission

- thorough peer review by experienced researchers in your field

- rapid publication on acceptance

- support for research data, including large and complex data types

- gold Open Access which fosters wider collaboration and increased citations

- maximum visibility for your research: over $100 \mathrm{M}$ website views per year

At BMC, research is always in progress.

Learn more biomedcentral.com/submissions 